\title{
Determinant factors of fire recurrence in Cerrado: focus in vegetation recuperation and aids for protected areas management
}

\author{
Ana Clara C. Q. Pôrto ${ }^{*}$, Camila S. Silva ${ }^{2}$, Juan Carlos O. Filho ${ }^{2}$,Jonathan V. Braga ${ }^{2}$, Angela B. Garda ${ }^{2}$, \\ Christian N. Berlinck ${ }^{2}$
}

\footnotetext{
${ }^{1}$ University of Brasília (UnB), Brasília, Brazil

${ }^{2}$ Chico Mendes Institute for Biodiversity Conservation (ICMBio), Brasília, Brazil

*Correspondence to: ac.caixeta.queiroz@gmail.com
}

\begin{abstract}
The occurrence and propagation of fire is determined by several factors such as meteorological conditions, seasonality, topography and accumulation of biomass fuel. However, the anthropic influence has generated a negative impact despite the natural fire history in the Cerrado. This study aimed to investigate the temporal and spatial patterns of fire in two federal protected areas: Serra Geral do Tocantins Ecological Station (Esec) and Nascentes do Rio Parnaíba National Park (Parna), from 2010 to 2017, in order to identify determining factors of fire occurrence and obtain data to assist the fire management in these areas. Remote sensing was used for burned area (BA) delineation, frequency evaluation and distribution. Linear models were applied to indicate which factor - monthly precipitation (MP), number of days without rain (NDR), vegetation type (Normalized Difference Vegetation Index - NDVI) and the interaction between NDRxNDVI - is most related to annual BA. NDVI values were obtained before passage of the fire to represent the fire hazard potential. The coefficients of determination $\left(\mathrm{R}^{2}\right)$ for BAxNDR and BAxMP were 0.438 and 0.424 for Esec, and 0.371 and 0.353 for Parna. The BAxNDVI ratio for Esec presented a $\mathrm{R}^{2}=0.040$, while NDRxNDVI and BA resulted in a $\mathrm{R}^{2}=0.214$. For Parna, the $\mathrm{R}^{2}$ were 0.080 and 0.092 for $\mathrm{BAxNDVI}$ and BAxNDRxNDVI. These values indicate rainfall as the most determinant factor for the occurrence of fires in these Cerrado areas. The fact that vegetation has presented a lower relation with BA or, in other words, has explained just a little of fire occurrence, can be caused by the predominant sandy, with a few nutrients and high percolation type of soil; as well as the distribution of phytophysognomies and relief. The data obtained in this study may help in the definition of improved fire management tactics, allowing prediction of the appropriate conditions for prescribing burns, as well as indicating situations of danger especially related to the accumulation of biomass fuel, helping to combat wildfires. Although, it is still necessary to incorporate other factors into the analyzes.
\end{abstract}

Keywords: biomass, burned area, rain regime, fire frequency. 